\title{
Layers of Reflexive Learning
}

\author{
Jennifer Berlingieri \\ The MIECAT Institute, Australia
}

Keywords: multimodality, reflexivity, dual awareness, layers, collaboration

I'd like to offer some highlights of the experiential, creative methods of teaching that my co-facilitator, Jacqui Grace, and I offered to MIECAT second year Master's students in 2018, in a companioning skills subject. We adopt a collaborative approach to teaching, and the processes I describe here are the result of a number of years of contributions from a variety of academic staff.

This subject focusses on students developing their practical skills in companioning others, in order to strengthen such aspects as: their quality of presence, relational attunement, adaptability, ability to work ethically and maintaining trust and safety, amongst others. We invite students to be present to what they notice about the way they companion another, and what they identify they would like to improve about their companioning practice. We used the term 'learning edges' to articulate these areas of growth for our students. Generally speaking, some learning edges that might emerge for students might be: struggling to stay present, being distracted by wanting to get it right, or feeling tempted to rescue the other.

Over the subject, our students were invited to use many modalities and creative processes to inquire further into their learning edges. Students identified their patterns of behaviour related to their learning edges, then multimodally mapped them, in order to see how these patterns might arise in other areas of their lives.

In order to foster reflective and reflexive practice in our students, we encouraged them to use their learning edges as the content of their inquiry, so that with every companioning round, they inquired into their learning edges as inquirer, then deepened that learning by working as companion again.

A key feature of this subject was an ongoing collaborative process of multimodally engaging with what we termed a 'Landscape of Learning Edges'. It started as an expanse of blank brown paper on the wall, and over the five days of the subject, students engaged with it and added to it a number of times. There were many ways we facilitated students to interact with this landscape in order to further their learning. First, we invited them to work in small groups to visually represent their learning edges using a topographical theme, and to then install them onto the landscape. They came up with such metaphors as 'The Cave of Hidden Knowing' and 'Mt Rigid', shown in Figures 1 and 2 .

After further inquiry, we asked students to create a tool to support their growth in their learning edge (Figure 3). 


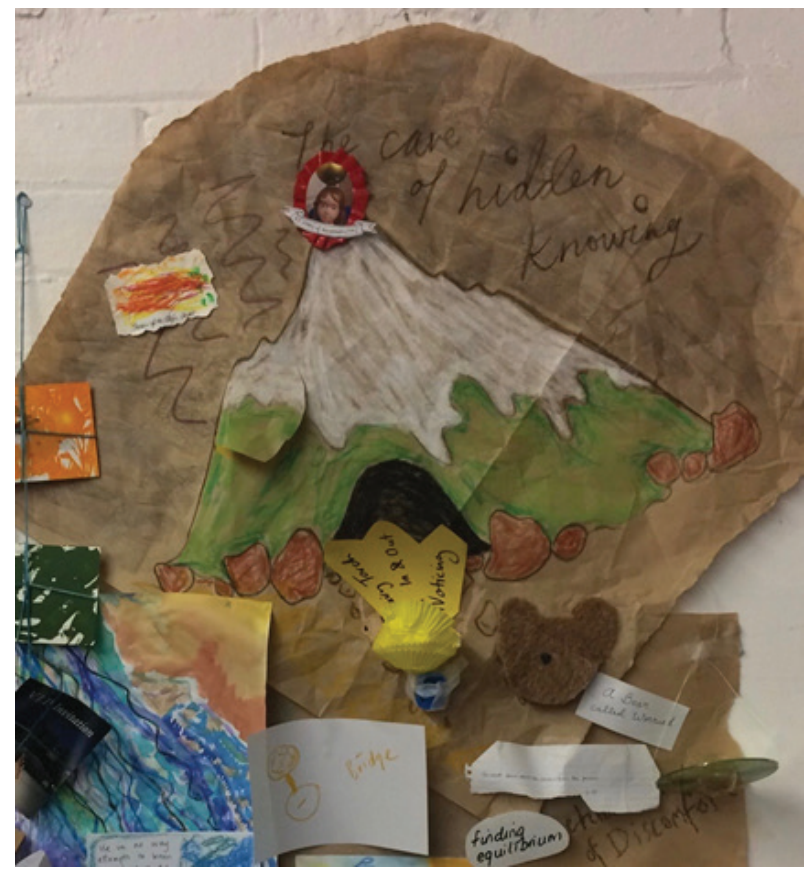

FIGURE 1 | MIECAT students, Detail of Learning Landscape, 2018, multimedia on paper, varying dimensions.

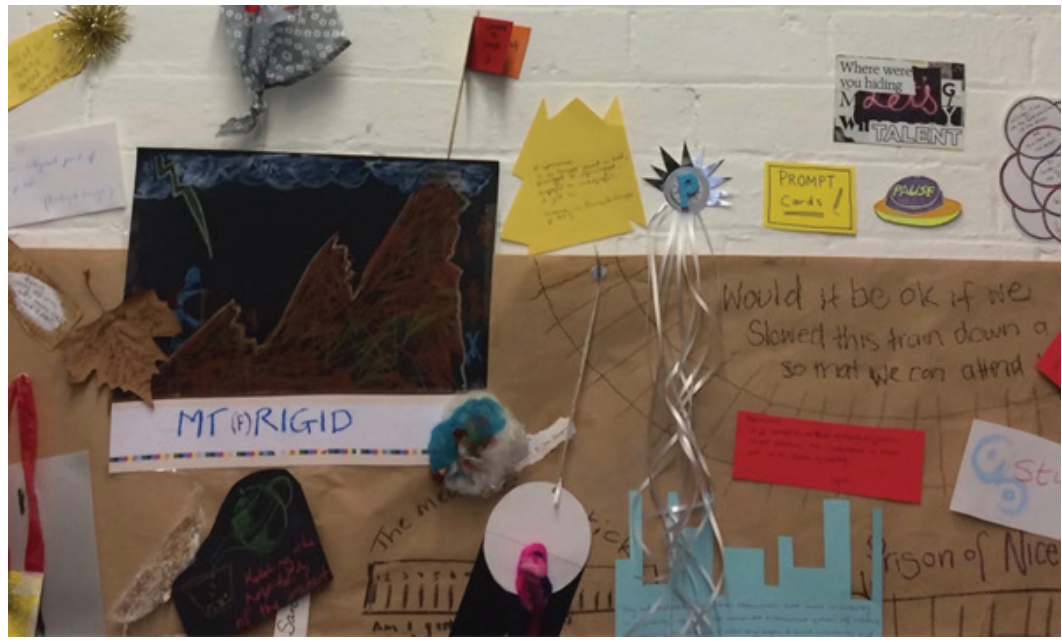

FIGURE 2 | MIECAT students, Detail of Learning Landscape, 2018, multimedia on paper, varying dimensions. 


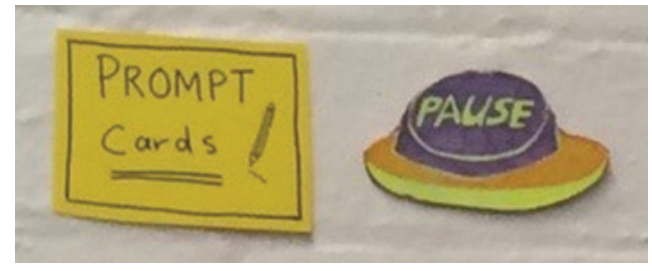

FIGURE 3 | MIECAT students, Detail of

Tools in Learning Landscape, 2018, multimedia on paper, varying dimensions.

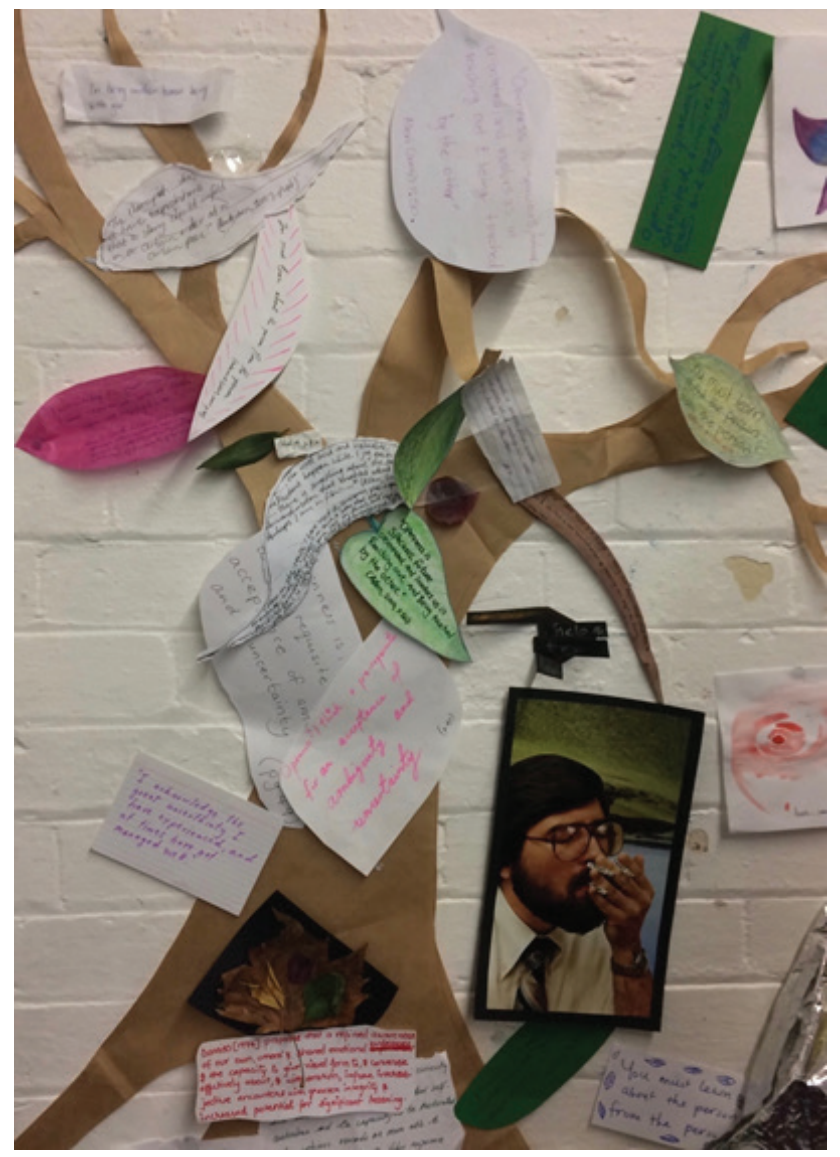

FIGURE 4 | MIECAT students, Learning Tree, 2018, multimedia on paper, varying dimensions. 


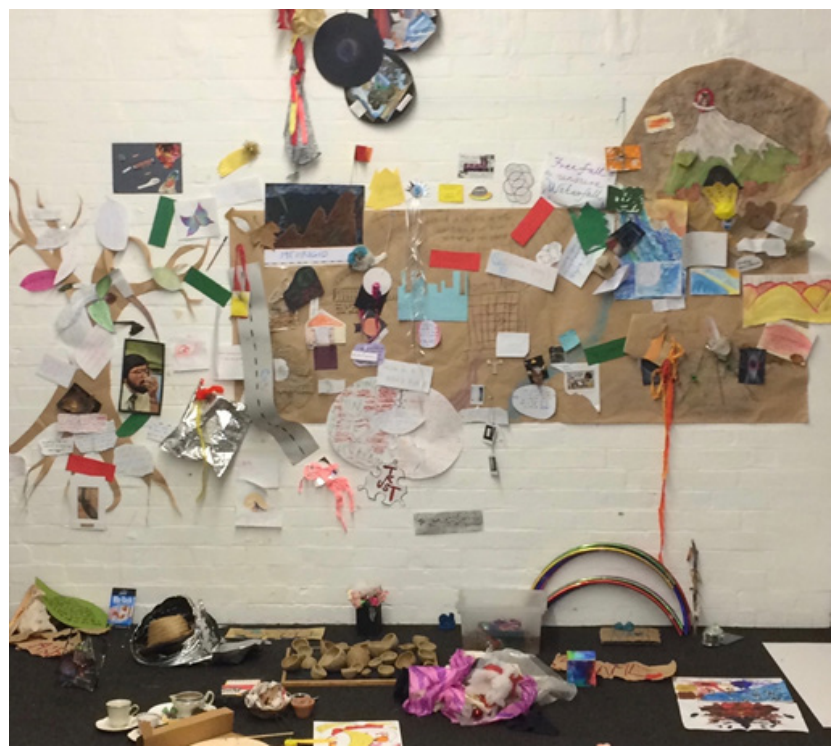

FIGURE 5 | MIECAT students, Final Learning Landscape, 2018, multimedia, varying dimensions.

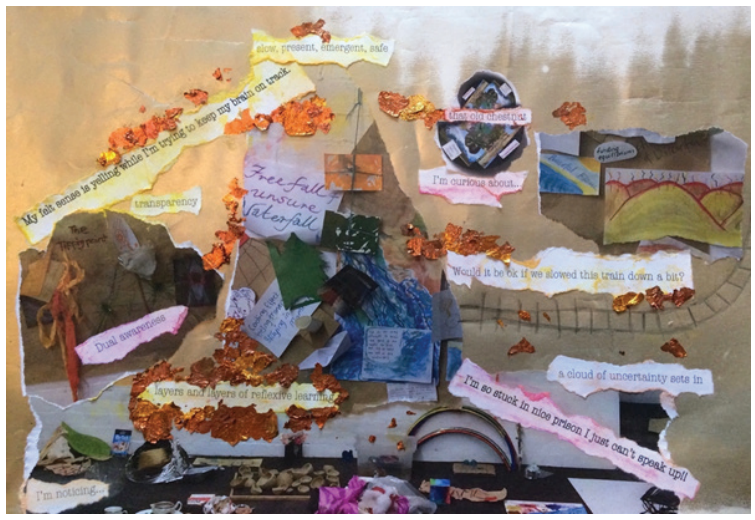

FIGURE 6 | Jennifer Berlingieri, Layers of Reflexive Learning, 2018, paper, pastel, gold leaf, $40 \times 30 \mathrm{~cm}$.

We also created a 'Learning Tree', where students daily added leaves containing quotes from the selected readings that resonated with them most (Figure 4).

As a whole group, over the five days, we repeatedly visited and revisited the Landscape. Students continued to install more work, layer upon layer, and respectfully witnessed each other doing the same. Eventually, the artwork evolved into three-dimensional pieces and further installations, creating the finished work shown in Figure 5.

To me, the Landscape became our home base. It was a large group of twenty eight students, but through these creative processes, and the generosity and willingness of all involved, the space of the landscape seemed to hold a sense of connection between us. 


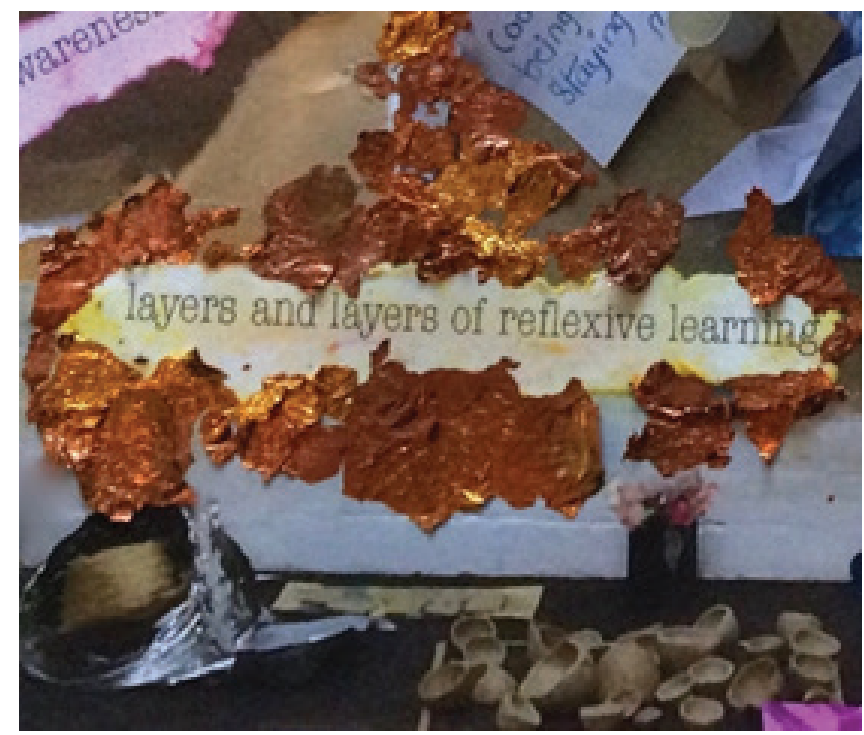

FIGURE 7 | Jennifer Berlingieri, Detail Layers of Reflexive Learning, 2018, paper, pastel, gold leaf.
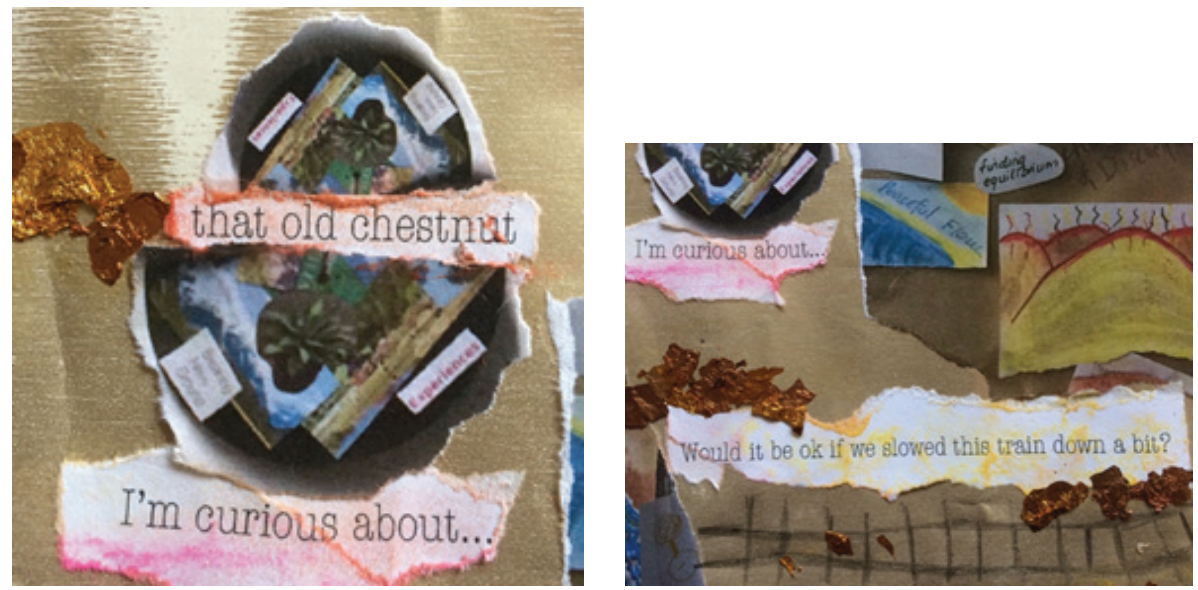

FIGURES 8 AND 9 | Jennifer Berlingieri, Detail Layers of Reflexive Learning, 2018, paper, pastel, gold leaf.

It was the place we all came back to, to reflect upon the learning and the multiple levels of experiencing. For me, landing together back in the landscape felt akin to arriving home for dinner after a big day, tired but alive with richness.

A teaching tool we use at MIECAT is the offering of creative responses to our students as part of the feedback for their work. Students are also encouraged to offer 
creative responses to their inquirers as part of their companioning work. As a creative response to my experience of teaching this subject, I've made this artwork, 'Layers of Reflexive Learning' (Figures 6-9), which I've shared with our students. I've collaged together images of the students' work, with phrases that I feel capture some of the key learnings. Keywords and phrases from this work are: layers of reflexive learning, dual awareness, transparency, present and emergent. This was my way of bringing all the layers of the reflexive learning experience together, that of the students and of myself as well.

\section{Acknowledgements}

Acknowledgements and gratitude to our students who have granted permission to use photos of their work, and to my co facilitator in teaching this subject, Jacqui Grace. Also, acknowledgement and appreciation to all MIECAT staff who have contributed to this subject in past years.

\section{About the Author}

Jennifer Berlingieri (M.A.) is a Creative Arts Therapist and Artist, who teaches and supervises Master's students at MIECAT, Melbourne, as well as works in private practice. She has particular interests in mental health, embodiment practices and multimodal learning. 